\section{PROGRESS IN CANCER REGISTRATION}

\section{A SURVEY OF THE DEVELOPMENT OF A CANCER RECORDS BUREAU FROM 1945 TO 1954}

\author{
BY
}

REGINALD M. VICK, M.Chir., F.R.C.S.

Director of South-western Regional Cancer Records Bureau; Consulting Surgeon to St. Bartholomew's Hospital

The first steps in the introduction of a scheme for recording cases of cancer on a national basis were taken by the Radium Commission, which, from 1930 until the National Health Service Act of 1946, controlled the supply of radium to the radiotherapy centres. During the war the collection of records from the centres was suspended.

In 1939 the Cancer Act required the council of every county and county borough to make and submit for the approval of the Ministry of Health arrangements for adequate facilities for treating cancer patients in their area. They were also advised to provide for the keeping of records, which were to be submitted ultimately to an authority designated by the Ministry. In 1944 the Ministry instituted registration cards and abstract cards for approved centres. The Radium Commission introduced similar arrangements for their centres. In June, 1945, the Radium Commission was nominated temporarily as the statistical bureau for collection and analysis of cancer records. This duty was taken over by the General Register Office in 1947, with whom it rests to-day.

\section{Formation of the South-western Regional Bureau}

When the war was over, the county councils of Gloucestershire, Somerset, and Wiltshire and the county boroughs of Bristol, Bath, and Gloucester got to work. They formed a cancer advisory committee and appointed the late Professor Rendle-Short as medical adviser. At that time they were responsible not only for records but for the facilitation of the diagnosis of cancer, for the treatment of patients suffering from that disease, and for the payment for care, maintenance, and travelling expenses of all such patients. One other point should be emphasized here-the principle, strongly supported by the Ministry, was that hospitals should not be recognized for service under the Cancer Act unless the surgical staff were whole-time consultants not engaged in private practice. This caused many delays and hampered the development of the scheme.

A records office was, in the first instance, established at the Bristol General Hospital, a records officer was appointed and subsequently four clerks to assist him, the whole under the clinical control of the medical adviser, and the administrative control of the house governor of the teaching group of hospitals. This organization worked smoothly, and by March, 1948, about 2,500 new cases were dealt with annually and 1,900 survivors were followed up, making a total of 4,400 cases handled.

Similar arrangements were made in Plymouth for the counties of Devon and Cornwall, and Mr. Duncan-Wood was appointed director for that area in 1947. It was not until 1948 that the Royal Devon and Exeter Hospital and the Torbay Hospital (Torquay) were included.

The Cancer Act was repealed by the passing of the National Health Service Act in 1946, and on the appointed day in 1948 the Regional Hospital Board took over the whole organization of the South-western Region, with offices at Bristol and Plymouth and cancer record clerks at Redruth, Torbay, and Exeter.
In 1952 the medical adviser at Bristol and the director at Plymouth resigned and one director was appointed in charge of the entire region and the two offices (October, 1952). Some co-ordination between the two areas had already taken place, but each area produced its own report in its own chosen form. In 1952 the reports of cancer statistics for the two areas were combined in one volume, but in 1953 the figures for the whole region were grouped together and critically analysed under each site of cancer in the body.

As both offices had been running-though only covering a much smaller number of hospitals-since 1945, it has been possible to produce a five-year survival rate for the entire region, and since 1948 all hospitals in which cancer is treated have been included. Thus a much more valuable statistical review has been possible.

\section{Advances in Registration}

Further advances in cancer registration are being carried out. An effort is being made to get as near the $100 \%$ registration as is possible. In order to do this, hospitals of al types (including mental hospitals, geriatric units, etc.) have been prevailed upon to send in records of their cancer patients. Medical officers of health have co-operated by sending in detailed returns of all cancer deaths at regular intervals. The analysis of these returns is providing much useful information, not the least important of which is the pin-pointing of those hospitals which are failing to register their patients with the bureau. It is hoped, ultimately, to register even those patients who never go into hospital at at. Surgeons throughout the region have been asked to register their private patients with the bureau, and the majority of them have agreed to do so.

Every patient registered has a case-history sheet, which contains all the available details, often from more than one hospital. From this history an abstract card is prepared, giving essential information, which is passed on to the office of the Registrar-General. Marginal punch cards are also prepared for every patient registered, and these cards are of inestimable value in any survey that may be required, such as the annual report, and for any special statistical investigation that is carried out. The information they contain is available to any surgeon who asks for it, and we have been able to answer many inquiries.

All these developments have greatly increased the number of registrations and the work of the bureau, which has entailed a small increase of staff.

\section{Personnel of the Bureat}

The personnel is now arranged as follows : (1) The director is responsible for the control of the work of the bureau and for the production of an annual report. This involves attendance at the two offices of the bureau, one in Bristol and one in Plymouth. (2) A records officer at each place : both of whom have been with the bureau since before the appointed day. (3) The requisite number of graded clerks - four at Bristol and three at Plymouth. Recently an extra clerk has been appointed at each office to cope with the rising tide of registrations. There are also cancer clerks at Exeter, Torbay, and Redruth.

\section{Annual Report, 1953}

Below is given an analysis of the annual report of the bureau for the year 1953-issued in December, 1954. The total population of the Region was 2,897,087 (1951 census), and Table $I$ indicates the work being done.

\begin{tabular}{|c|c|c|c|c|}
\hline \multirow{4}{*}{$\begin{array}{l}\text { Total No. of cases regis- } \\
\text { tered to end of } 1953 \\
\text { No. of new cases registered } \\
\text { in } 1953 \text {. } \\
\text { No. of cases followed-up } \\
\text { in } 1953 . .\end{array}$} & $\begin{array}{c}\text { TABL } \\
\text { Bristol }\end{array}$ & Plymouth & & $\begin{array}{c}\text { Combined } \\
\text { Total }\end{array}$ \\
\hline & 23,136 & 16,043 & .. & 39,179 \\
\hline & 3,883 & 2,705 & .. & 6,588 \\
\hline & 10,000 & 6,183 & .. & 16,183 \\
\hline
\end{tabular}

The report is circulated to all the regional hospital boards, to every surgeon in the region who treats patients suffering 
from cancer, to all hospitals and medical officers of health within the region, to the Ministry of Health, the General Register Office, to all relevant medical committees, including local medical committees, indicating that more copies are available for any interested general practitioners, to all radiotherapeutic departments, to all medical schools in the British Isles, and to the medical press.

It shows the state of registration in 1953 for each hospital in the two areas, the distribution of registrations by counties, and, in the Plymouth area, is accompanied by special tables showing the distribution of cancer registration in clinical areas. The report contains statistical tables which indicate under each anatomical site the total number of patients treated in both the Northern (Bristol) and the Southern (Plymouth) areas, the method of treatment, and the number of survivors. It indicates the five-year + survival rate under each site and comments on the clinical history of the survivors.

Beneath the heading of certain "accessible" sites-the breast, cervix uteri, and uterus - the patients are classified under the recognized stages (Manchester staging) and the curvival rate is indicated under each stage. When the numbers of untreated cases appear to be of statistical significance they are given.

The order in which the malignant growths are taken follows, so far as is possible, the classification of the World Health Organization. Two examples of the way in which the statistical tables are set out are shown in Tables II and III.

TABLE II.-Malignant Growths of Large Intestine (Excluding Rectum)

\begin{tabular}{|c|c|c|c|c|c|c|}
\hline & & & \multicolumn{2}{|c|}{ Total Cases } & \multicolumn{2}{|c|}{ Patients Alive } \\
\hline & & & Bristol & Plymouth & Bristol & Plymouth \\
\hline $\begin{array}{l}\text { Radical surgery } \\
\text { Palliative } \\
\text { Not treated .. }\end{array}$ & $\begin{array}{l}. . \\
\because .\end{array}$ & $\begin{array}{l}. . \\
\because .\end{array}$ & $\begin{array}{l}95 \\
71 \\
76\end{array}$ & $\begin{array}{l}62 \\
50 \\
35\end{array}$ & $\underline{41}$ & $\begin{array}{r}31 \\
5 \\
-\end{array}$ \\
\hline \multirow{2}{*}{\multicolumn{2}{|c|}{. Total }} & & 242 & 147 & 41 & 36 \\
\hline & & $\cdots$ & \multicolumn{2}{|c|}{389} & \multicolumn{2}{|c|}{77} \\
\hline
\end{tabular}

The comments on survivors in Table II are as follows: Age-youngest 32 ; sex-men 27, women 50 . Treatment :Partial colectomy, 60 ; exteriorization and subsequent closure of colostomy, 12 ; colostomy only, 3 ; surgery and radiotherapy, 2. Sites :-Sigmoid and pelvic colon, 31 ; transverse colon, 12 ; caecum, 7 ; ascending colon, 6 ; descending colon, 6 ; hepatic flexure, 5 ; splenic flexure, 5 ; rectosigmoidal junction, 5 .

TABLE III.-Malignant Growths of Mouth (Excluding Tongue)

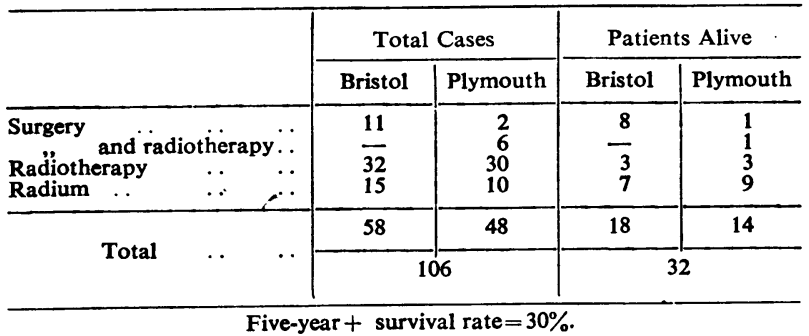

The comments on survivors in Table III are as follows: Age-youngest 30 , oldest 83 ; sex-men 23 , women 9 . The series includes one case of rhabdomyoma of the cheek, treated by excision. Sites :-Floor of mouth, 10 ; alveolus, 7 ; palate, 6 ; cheek, 5 ; tonsil, 2 ; lower jaw, 1 ; fraenum, 1. Biopsy was positive in most cases.

Space does not allow of the setting out of all the tables in extenso. In Table IV is given a summary of the figures under each anatomical site. The breast, cervix, and uterus are dealt with in a later table.
TABLE IV.-Summary of Registrations According to Anatomical Site

\begin{tabular}{|c|c|c|c|c|}
\hline \multicolumn{2}{|c|}{$\begin{array}{l}\text { Site of } \\
\text { Malignant Growth }\end{array}$} & $\begin{array}{l}\text { Total } \\
\text { Cases }\end{array}$ & $\begin{array}{l}\text { Patients } \\
\text { Alive }\end{array}$ & $\begin{array}{l}\text { 5-year+ } \\
\% \text { survival }\end{array}$ \\
\hline Lip & .. & 256 & 142 & 55 \\
\hline Tongue & & 141 & 25 & $17 \cdot 7$ \\
\hline Salivary glands & .. $\quad .$. & 54 & 34 & 63 \\
\hline Mouth (excluding & g tongue) & 106 & 32 & 30 \\
\hline Pharynx, larynx, & etc. .. & 170 & 25 & \\
\hline Oesophagus & .. & 203 & 4 & 2 \\
\hline Stomach ... & $\therefore \quad \ldots \quad \ldots$ & 492 & 25 & 5 \\
\hline Large intestine (e) & xcluding rectum) & 389 & 77 & 20 \\
\hline Rectum .. & .. $\quad . . \quad .$. & 437 & 61 & 14 \\
\hline Pancreas .. & .. & 40 & 1 & 2.5 \\
\hline Thoracic organs & .. & 408 & 11 & 2.7 \\
\hline Ovary $\quad .$. & .. & 179 & 43 & 24 \\
\hline Prostate & .. & 206 & 30 & 15 \\
\hline Testis & .. & 59 & 35 & 59 \\
\hline Penis & .. & 56 & 24 & 43 \\
\hline Kidney & $\therefore$ & 59 & 17 & 29 \\
\hline $\begin{array}{ll} & \\
\text { Bladder } & . . \\
\end{array}$ & $\begin{array}{ll}. . & \ldots\end{array}$ & 163 & 38 & 23 \\
\hline Skin (malignant & melanoma) & 79 & 25 & 32 \\
\hline & & 18 & 11 & 61 \\
\hline Brain and central & I nervous system & 29 & 9 & 31 \\
\hline Thyroid .. & te & 52 & 15 & 29 \\
\hline Bone & $\ldots$ & 137 & 16 & $11 \cdot 6$ \\
\hline $\begin{array}{l}\text { Lymphadenoma } \\
\text { Leukaemia }\end{array}$ & $\begin{array}{ll}. . & . . \\
. & .\end{array}$ & $\begin{array}{l}120 \\
125\end{array}$ & $\begin{array}{r}33 \\
9\end{array}$ & $27 \cdot 5$ \\
\hline
\end{tabular}

Comments on some of the five-year+ survival rates shown in Table IV are as follows.

Lip.-It is distressing to note the relatively high mortality for what is, after all, an "accessible" cancer. Many of the patients presented themselves at a late stage and were treated by radiotherapy.

Tongue.-The high mortality of cancer of the tongue is demonstrated. No fewer than 48 of these patients presented themselves late and were treated by radiotherapy alone. Only two of these survived for five years.

Salivary Glands.-Parotid glands involved in 31 survivors, submandibular in only 3 . All proved malignant cases.

Oesophagus.-The appalling mortality of cancer at this site is illustrated.

Stomach.-This includes nearly 500 cases with only $5 \%$ survival. No fewer than 3 patients thought to be inoperable in 1948 or earlier are alive and well to-day.

Large Intestine.-Already dealt with.

Rectum.-34 abdomino-perineal survivors, 11 perineal, 6 conservative resection, 2 with hysterectomy, and 2 inoperable.

Pancreas.-Evidently no cases of mistaken diagnosis in this series.

Thoracic Organs. -7 of the survivors treated by pneumonectomy, 4 by radiotherapy only.

Testis.-Surprisingly high survival rate. 26 seminomata, 6 teratomata, 1 adenocarcinoma. No pathological report in 2 cases. In only one patient were the testes not in the scrotum.

Malignant Melanoma of Skin.-32\% alive and well to-day. All proved malignant melanoma histologically. 5 cases excision only; 15 excision and radiotherapy with 7 removal of glands ; 4 wide removal.

Thyroid.-Total thyroidectomy and radiotherapy in 2 cases. Partial thyroidectomy and radiotherapy in 9 cases. Radiotherapy alone 3 cases. Radium after wedge resection 1 .

Bone.-Seven cases of osteogenic sarcoma amongst the survivors.

All the figures in Table $\mathrm{V}$ and throughout the report cover the work of a considerable number of surgeons, and every patient was treated between 1945 and 1948 .

The table indicates that the earlier the condition is diagnosed and efficiently treated the better the prognosis. The later the stage the higher the mortality. 
TABLE V.-Some Five-year Survival Rates

\begin{tabular}{|c|c|c|c|}
\hline $\begin{array}{l}\text { Site of Malignant } \\
\text { Growth and Stage }\end{array}$ & $\begin{array}{l}\text { Total } \\
\text { Cases }\end{array}$ & $\begin{array}{l}\text { Patients } \\
\text { Alive }\end{array}$ & survival \\
\hline $\begin{array}{ccc}\text { Breast: } & & \\
\text { II } & \ldots & \ldots \\
\text { III } & \cdots & \ldots \\
\text { IV } & \cdots & \ldots\end{array}$ & $\begin{array}{l}531 \\
328 \\
107 \\
228\end{array}$ & $\begin{array}{r}1 \\
331 \\
130 \\
33 \\
18\end{array}$ & $\begin{array}{r}62 \\
40 \\
31 \\
8\end{array}$ \\
\hline $\begin{array}{ccc}\text { Cervix: } & & \\
\text { II } & \ldots & \ldots \\
\text { III } & \cdots & \ldots \\
\text { IV } & \ldots & \ldots\end{array}$ & $\begin{array}{r}73 \\
102 \\
93 \\
32\end{array}$ & $\begin{array}{r}43 \\
35 \\
17 \\
4\end{array}$ & $\begin{array}{l}59 \\
34 \\
18 \\
13\end{array}$ \\
\hline $\begin{array}{c}\text { Uterus: } \\
\text { Early } \\
\text { Late }\end{array}$ & $\begin{array}{r}123 \\
88\end{array}$ & $\begin{array}{l}76 \\
21\end{array}$ & $\begin{array}{l}62 \\
24\end{array}$ \\
\hline
\end{tabular}

\section{Summary}

An account is given of the gradual development of a regional cancer records bureau.

In view of the increasing interest in cancer registration, it is hoped that this account may help those who are in the process of organizing such centres.

An analysis of the statistical review contained in the annual report of the bureau is given-showing total number of cases under each anatomical site and number of survivors. A five-year + survival rate is given in percentages under each site. A clinical survey of survivors is detailed.

Under certain " accessible" cancers the survival rate at the various stages of the disease is indicated and the vital importance of early diagnosis and treatment is stressed.

My thanks are due to the officers of the South-western Regional Hospital Board for their unfailing help, and to the cancer records officers, without whose help this report could not have been compiled.

\section{EPISTAXIS}

At the clinical meeting for general practitioners held at the Institute of Laryngology and Otology, Gray's Inn Road, London, on February 11, Mr. C. Gill-Carey discussed "Epistaxis."

Nine out of every ten cases of epistaxis were not serious, he said, in that there would be no grave underlying disease or risk of undue blood loss. But nose bleeding caused alarm, and the doctor's prestige was enhanced by efficient treatment. Most often the source of the bleeding was on the septum anteriorly, and could be controlled without tight packing by using a small plug of some non-irritating material such as gauze or cotton-wool impregnated with petroleum jelly or bismuth, aided by digital pressure on the ala nasi by the patient. If the bleeding recurred and cauterization became necessary, Mr. Gill-Carey suggested local infiltration with procaine and adrenaline injection (B.P.) before the removal of the plug. This would produce temporary haemostasis as well as analgesia of the nasal skin and mucous membrane. For severe bleeding from the anterior part of the septum he advised coagulation by diathermy.

\section{When is it Serious?}

Epistaxis, even when mild, might be the first sign of some serious underlying disease, such as a blood disorder, a malignant neoplasm in the nose, hypertension, or diphtheria. These and other possibilities, although not common, had always to be borne in mind.

Arterial disease was responsible for most cases of intractable bleeding, and in a third of them the bleeding artery was relatively inaccessible. Such patients were seldom benefited by a combination of nasal and post-nasal plugging. It was better to ligate the internal maxillary artery via the antrum or the ethmoidal arteries through an orbital incision. In these patients there was a real danger of coronary throm- bosis if the blood flow was allowed to continue unchecked for too long.

Replying to questions, Mr. Gill-Carey expressed a poor opinion of ice in treatment : it had little effect on the bleeding. Nor did he advocate soaking plugging material in vasoconstrictors such as adrenaline, as vasodilation would follow the vasoconstriction. Packing an already infected nose, he agreed, increased the risk of sinusitis, and if packing was necessary for more than a few hours systemic antibiotic therapy should be given. Asked about the treatment of hereditary telangiectasis by ethinyloestradiol, Mr. Gill-Carey said that one of his own cases had been' partially controlled by it, and that the treatment appeared to offer real relief in this grave and crippling disease.

\section{Reports of Societies}

\section{CORONARY THROMBOSIS : ROLE OF DIET AND ATHEROSCLEROSIS}

A joint meeting of the Sections of Pathology and Epiderriology and Preventive Medicine discussed "Coronary Artery Disease" at the Royal Society of Medicine on March 1. Professor L. P. Garrod, president of the Section of Pathology, was in the chair.

\section{Morbid Anatomy of Atherosclerosis}

Professor T. CRAWford (Department of Pathology, St. George's Hospital, London) opened the discussion with an illustrated account of the morbid anatomy of coronary atherosclerosis in man. The yellowish-white plaques of atheroma were well known, but it was often difficult to tell from post-mortem examination what effect they had had on the calibre of the vessel. It was certainly not true that large plaques necessarily narrowed the lumen. $\mathrm{He}$ had studied this problem by injection techniques using stereoscopic radiography to demonstrate irregularity and narrowing, which were particularly common in the descending branch of the left coronary artery. Normally the intima of the coronary arteries was thicker than that of comparable arteries elsewhere, even in young children. Sections through the earliest lesions showed a slightly thickened intima in which a varying amount of fat had appeared. This might be either diffusely scattered or collected into the cytoplasm of macrophages which came to lie in groups immediately beneath the endothèlium. A varying amount of the material was birefringent, and chemical examination showed the presence of cholesterol and its esters as well as neutral fats. In more advanced lesions the fatty material was separated from the lumen by a progressively thicker layer of rather acellular laminated collagen fibres. Eventually the lumen became distorted, and thrombosis was apt to occur.

If the patient survived the initial thrombosis, one of two things might happen : either a lumen was quickly re-established by retraction of the thrombus to the side of the vessel, or there was a more gradual recanalization of the thrombus by fusion of the capillaries which grew into it during the process of organization. These might eventually proliferate to form a type of cavernomatous transformation of the segment of vessel. However, this was often only of temporary benefit to the circulation because the thrombotic process was frequently repeated in the new channels. The most important recent advance in the understanding of atherosclerosis was the demonstration by Duguid that fibrin incrustations occur on the intima and are quickly covered by a fresh layer of endothelium. Organization of these fibrin deposits, continued Professor Crawford, took place both from the vessel lumen and from the vasa vasorum. Small incrustations thus became organized throughout and resulted in nothing more than some fibrous thickening of the intima : but larger or superimposed deposits might be incompletely organized, a layer of unorganized amorphous debris persisting between the zones of surface and medial organization. 